\title{
THE PEAK AND DECLINE OF WORLD OIL AND GAS PRODUCTION
}

by

\author{
K. Aleklett and C.J.Campbell \\ (Uppsala University, Sweden)
}

\begin{abstract}
Oil and gas have been known since Antiquity but the modern oil industry had its roots in the middle of the $19^{\text {th }}$ Century in Pennsylvania and on the shores of the Caspian. In the early days, the discovery of oil was a hit or miss affair, but in later years it became a decidedly scientific and technological process. Perhaps the most important development was a geochemical breakthrough in the 1980s that made it possible to relate the oil in a well with the rock in which it was generated. That in turn led to an understanding of the very exceptional conditions under which oil was formed in Nature. Advances in computer science also brought great progress in seismic surveying that made it possible to determine with great accuracy the nature of deeply buried geological structures.
\end{abstract}

These scientific advances have not however been matched by clarity in reporting the results, which are clouded by ambiguous definitions and lax reporting practices. In short, it has been another example of poor accounting. Estimating the size of an oilfield poses no great technological challenge, although there is naturally a quantifiable range of uncertainty. Extrapolating the discovery trend of the past to determine future discovery and production should be straightforward, and the size distribution of fields should be evident. But the atrociously unreliable nature of public data has given much latitude when it comes to interpreting the status of depletion and the impact of economic and political factors on production. This has allowed two conflicting views of the subject to develop.

The first is what may be called the Natural Science Approach, which observes the factors controlling oil accumulation in Nature and applies immutable physical laws to the process of depletion. It seeks to base its conclusions on three simple questions:

- what was found, referring to the different categories of oil and gas?

- how much was found? and

- when was it found?

(see Bentley, 2002; Campbell 1997,1998; Deffeyes, 2001; Laherrère 1999; Ivanhoe, 2000; Perrodon, 1999; Simmons 2000; Youngquist, 1997)

The second is what may be called the Flat-Earth Approach, in which the resource is deemed to be virtually limitless, with extraction being treated as if it were controlled only by economic, political and technological factors. It seeks to explain discovery as a consequence of investment, in the belief that supply always matches demand under ineluctable economic principles. It supposes that as one resource is depleted, its place is seamlessly taken by a better substitute: "the Stone Age did not end because we ran out of stone" is a favourite aphorism. (see Adelman, 1995; Odell, 1999.)

There is little scope for consensus because one approach relies on the measurement and observation of Nature, the other on faith in the Mastery of Man. The debate, if that is the right word, is itself further clouded by vested interests with motives to obscure and confuse. On the one side have been the oil companies who have had good commercial 
and regulatory reasons to under-report the size of discovery, so that the subsequent upward revisions gave an encouraging image of steady growth to the stockmarket. On the other side are governments and international agencies that have found it easier in political terms to react to a crisis than to anticipate one. The depletion of oil, which furnishes $40 \%$ of traded energy and $90 \%$ of transport fuel is by all means a sensitive subject for all governments because it heralds a discontinuity of historic proportions. It is easy for the economists who advise most governments to map short-term economic cycles but it is very difficult for them to deal with major discontinuities, especially those that undermine the very foundations of their subject.

This paper will endeavour to present the evidence for the Natural Science Approach, addressing the geological constraints; the technical basis of reserve estimation; the distribution of field sizes; and the obvious correlation between discovery and production after a time lag. It will further explain the reporting practices, and present both a realistic assessment of the resource and a practical model of depletion.

\section{Geological Constraints}

The exploration process involves the search for geological structures that have the perceived potential for containing oil and gas. In this discussion, it is convenient to refer collectively to oil and gas as simply oil, except where there is a need to distinguish the two phases. When a new area was opened to exploration, the industry moved in to collect geological information. In earlier onshore exploration, geologists studied the outcrops with technology no more advanced than the hand lens and the hammer, and found the bulk of the world's oil in this way. The surface observations were increasingly complemented by information from seismic surveys, which showed the subsurface structural configuration of the rocks but could not indicate their composition. That knowledge had to come from boreholes, which secured cores and samples from the drill cuttings brought to the surface by the circulating mud used in the drilling process. Additional information came from sondes lowered down the wellbores to measure the physical properties of the rocks.

In the Soviet Union, the explorers had the luxury of drilling boreholes simply to gain information and hence better direct their search, but in the West only prospects that were perceived, or depicted, as having a good potential of finding a profitable oilfield could be tested. The difference between scientific perception and commercial depiction opens the first door to the confusing reporting practices, which are so deeply entrenched in the business.

A prospect has to meet certain very well understood criteria, principal amongst which are the following elements:

\section{Source Rock}

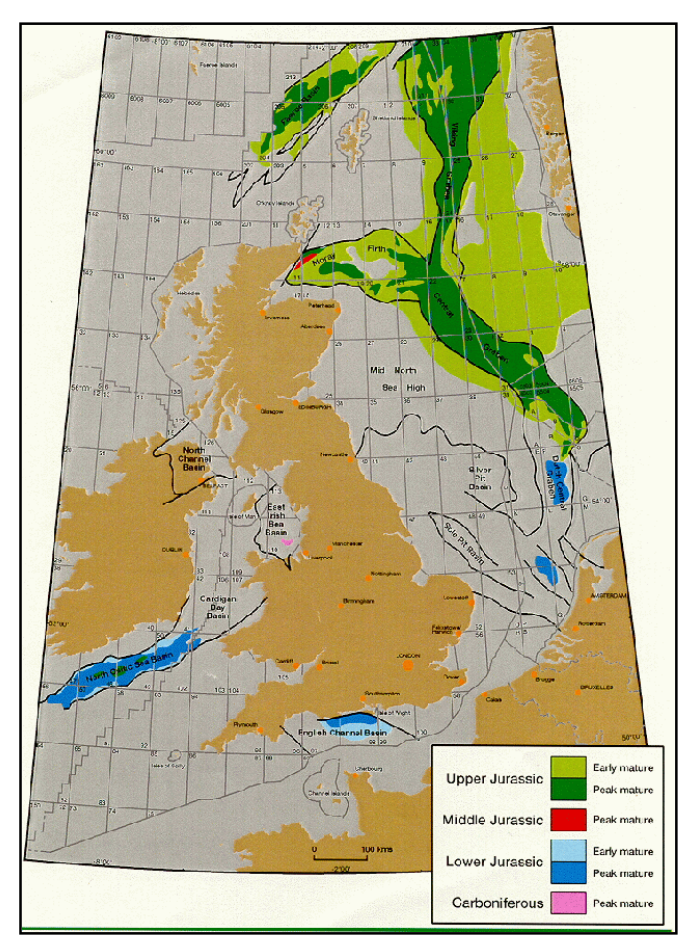


It has to be in communication with a rock capable of generating oil, termed a sourcerock. Although such can occur locally at any level in the geological record, the great bulk of the world's oil is derived from two brief epochs, occurring respectively 100 and 150 million years ago. The Earth was subjected to intense global warming at those times, causing the proliferation of algae, which effectively poisoned the contemporaneous lakes and seas. The organic material, so formed, sank to the anoxic stagnant depths of rifts where it was preserved and duly buried by younger sediment. It was subjected to the Earth's heat-flow on burial, with the so-called Oil Window being normally reached at a depth of about $2000 \mathrm{~m}$ when temperatures were sufficient to convert the organic material into oil. Gas is formed in a similar fashion save that it comes from vegetal material rather than algae, and is also formed in places where oil is depressed below the oil window into very high temperatures that break down the oil molecule.

Most of the world's oil prolific generating zones have now been mapped in fair detail, but there always remains the possibility of turning up an unexpected small and localised development.

We may also mention - and confidently dismiss - an alternative theory that oil and gas were generated during the early stages of the Earth's formation, as proposed by a physicist (Gold, 1988). The theory was unsuccessfully tested at huge cost in Sweden and has been universally dismissed by the oil companies, although it still retains a few adherents, who are occasionally paraded by the flat-earth faction in support of their faith in infinite resources.

\section{Migration}

The chemical reactions responsible for oil formation involve expansion, such that the oil is born under very high pressure, sufficient to fracture the overlying rocks, allowing it to move upwards to zones of lesser pressure. In the event that it encounters a porous and permeable formation, such as a sandstone, the oil preferentially flows through it, moving under the influence of buoyancy to displace the water that naturally occupies the pore space in the rock. Oil and gas may become separated from each other in the course of migration, filling different traps, and re-migration may occur from changed structural conditions. If the migration conduit extended to the surface at the edge of the geological basin, the oil escaped to the atmosphere. The huge deposits of heavy degraded oil that occur on the margins of basins in Eastern Venezuela and Western Canada are residues, from which the light fractions have escaped, partly as a result of bacteriological action.

\section{Trap}

In the event that the conduit, through which the oil migrateding, has been deformed by earth movements into folds, or cut by faults, the oil collects at the highest part of such traps, where commonly a gas cap also separates. The oil and gas will however gradually leak upwards unless the structure is capped by an effective seal in the form of clay, or better, salt. Much has been lost over geological time as no seal has perfect integrity.

The oil in the trap is held in the pore space of the rock, which is termed the Reservoir. Pore-space comprises the space between the grains making up the rock, which are normally filled with water. Most effective oil reservoirs have porosity in the range of 20 
to 30 percent by volume. The individual grains are normally coated with a thin firm of residual water, which may coalesce and block the movement of oil, adversely affecting its permeability. The grains too may be poorly sorted, with fine material clogging the porosity. It is easy to understand why only a fraction of the oil in the rock can be extracted, much being held there permanently by capillary effects. Average recovery is about $40 \%$, but it ranges widely depending on the characteristics of the oil and the reservoir. A reservoir has to have satisfactory porosity and permeability both for the oil to enter it in the first place and then to move towards the well-bores when it is being drained. A reservoir too may be far from a uniform sequence of porous rock, but contain barriers and isolated pockets of porosity which are not in communication.

\section{Measuring the Size of a Prospect}

If the prospect meets all the qualitative criteria, as summarised above, attention turns both to measuring its size, and evaluating its economic potential. The prospect as mapped by seismic surveys, which effectively provide a scan of the geology beneath the surface, can be contoured in much the same way as can a hill on the landscape to show both its relief and volume.

The starting point in determining the amount of oil that the prospect might contain is the gross rock volume of the trap, as indicated by the seismic surveys. It is more difficult to forecast the nature of the reservoir within it. That assessment has to be based on regional information or the results of nearby boreholes, but reasonable estimates of the net reservoir thickness, the porosity, the oil saturation, the recovery factor, and the degree to which the structure is full can usually be made. Clearly, the assumptions in an entirely new area are less sure than are those in a mature area.

If the geological assessment is reasonably promising, attention turns to making an economic evaluation, and "selling" the proposal to the management. Hypothetical economics are evaluated to take into account the size of the possible reserves, the cost of producing them, and the likely profit under assumed oil-price scenarios. Companies normally have hurdle rates, being willing to test only those prospects large enough to yield an acceptable rate of return. They generally operate with low oil price scenarios, not that they necessarily believe in them, but as a convenient cover against unexpected cost over-runs.

Selling the project to the management, which is not always well qualified to assess the actual geological merits, is a matter of salesmanship. If the best scientific estimate of its size fails to deliver the required economic justification, the proposal can be re-run under more optimistic assumptions. Politics enter into the process both internally within the company concerned and in relation to its partners or the host government. Often wells drilled primarily for information to evaluate new geological ideas or meet government drilling commitments have to be heavily disguised to pass the economic tests imposed by distant boardrooms.

In any event, the assessed reserves remain confidential to the company making them. In cases where more than one company is involved in a project, each will have its own 
estimate as required to meet its internal purposes and procedures. In some circumstances, such estimates have to be provided to governments in connection with competitive bidding, but little weight need be given to them as they are normally adjusted to give the desired image.

\section{Measuring the Size of a Discovery}

In the event that the explorers are successful in persuading their management to provide the funds, the prospect, and the ideas behind it, will be tested by drilling a so-called wildcat borehole. A typical offshore wildcat may cost as much as ten million dollars, and much more than that in deep water. The chances of success are slim, being about 1:10 for a discovery of any sort and perhaps as much as 1:100 for a sizeable find. The industry is used to accepting failure in exploration drilling, comforted by the knowledge that most of the cost is offset against taxable income.

If the wildcat is successful, attention turns to designing an optimal development plan. Onshore in Texas, for example, the first well may be put on production immediately, but offshore, it is necessary to build platforms capable of supporting a given number of wells. The challenge is to balance the investment in facilities against the level of production, it being normal to aim at an optimal plateau of production rather than a short peak followed by decline. The economic notion of the time-value of money encourages rapid depletion. The development of large fields normally takes place in phases. The first phase aims to recover the investment as quickly as possible by draining the most favourable part of the trap. Subsequent phases extend the production plateau for as long as possible by tapping subsidiary reservoirs and outlying pockets. Plateau production is held as long as possible to maximise the return on the sunk costs and because the tail end of a field is not normally very profitable. Every situation has its own particular characteristics. An onshore field in a mature area may just be progressively drilled up, whereas offshore and in remote locations the development is more complex involving pipeline construction and/or linkage to neighbouring facilities.

\section{Reporting the Size of a Discovery}

The reporting practices of the industry evolved long ago in the days of fairly primitive technology, being much influenced by conditions in the United States where the Securities and Exchange Commission (SEC) moved to impose rigorous controls for financial reporting purposes. Mineral rights in much of the United States belong to the landowner, which meant that the early oilfields had a very fragmented ownership. The industry has traditionally recognised three categories of reserves - Proved, Probable and Possible - with meanings the words convey. Proved Reserves, as reported for financial purposes, refer to the estimated future production of current wells, being commonly determined simply as ten times annual current annual production, which is another way of assuming a ten percent Depletion Rate. In plain language, the term means Proved-soFar, saying little about the size of the field as a whole, which in the early days of onshore Texas could not be readily determined in any case because of the highly fragmented ownership. It was a perfectly sound and logical system for the purpose it was used. 
Since most oil companies are quoted on the American stock exchange, the same reporting practices were applied offshore and internationally, although the circumstances were very different. Such fields were normally produced by an individual company, or by a group of companies working together, who did need to know full field reserves for the purposes of planning. But the same general principles of reporting Proved Reserves remained, although marginally relaxed to cover not only the proceeds of current wells but also the planned phases of development, including for example the contributions of water-flood and pressure maintenance. In practice, the rules were designed primarily to prevent fraudulent exaggeration, being not particularly concerned about under-reporting. The companies for their part found it expedient to release conservative estimates to be revised upwards over time, which had the effect of smoothing their assets, reducing tax and presenting the image of well managed gradual growth.

It will be remembered that discovery is an episodic and transcendental event accompanied by many failed endeavours. It is the birth of an undertaking without which nothing follows. It means that it is essential to backdate reserve revisions to the original wildcat to determine the real discovery trend, whereas for financial purposes the revisions are properly attributed to the date on which they are announced. It is vitally important to distinguish these two reporting practices because confusion between them lies at the heart of the dispute that divides

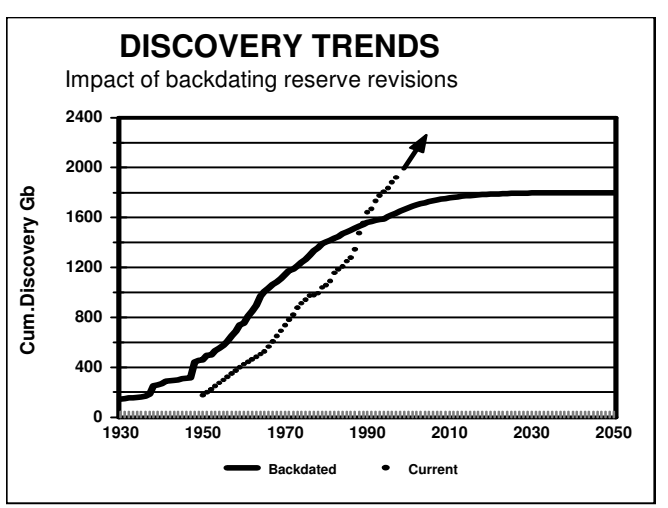
Natural Science from Flat-Earth Economics.

Knowledge of the size of a field improves over its life, to be known absolutely only on the date of its abandonment when no more oil is extracted from it. Production, as it proceeds, eats into reserves. The term Reserves may mean Remaining Reserves as of the reference date, or it may mean Initial or Original Reserves referring to the estimates before production began, but it is often obscure if the latter terms include or exclude subsequent revisions. The scope for confusion is great.

In plain language, the term Proved \& Probable Reserves is commonly taken to mean the best scientific estimate of the size of the field as a whole.

It is obvious that all estimates are subject to degrees of uncertainty, or in other words probability, which opens another Pandora's box of confusion. It is quite normal to apply probability theory to the technical assessment of reserves to integrate the ranges of a number of different parameters. A procedure known as Monte-Carlo Simulation is commonly applied to consider every possible combination of circumstance, and various arcane statistical methods are used to try to quantify the risks associated with developing an oilfield. This has led to another reporting practice by which alternative reserve estimates are plotted against their probability ranking. This procedure considers a Low Case, in which the Reserves are said to have a 90-95\% Subjective Probability of being greater than the stated value, and a High Case, having a 5-10\% Subjective Probability of 
being greater than the stated value. From this range can be computed Mean, Median and Mode values. The Mean value is taken to equate the Proved \& Probable Reserves.

Median Probability Reserves, termed $P_{50}$, are sometimes reported: it being said that the chances of the actual amount being higher or lower than the stated value are equally matched.

Some classifications equate Proved Reserves with $P_{90-95}$ Reserves under the Probabilistic system, but this fails to take into account that in reality Proved Reserves relate to the current stage of development whereas Proved \& Probable (Mean) Reserves relate to the full field. Both are subject to degrees of probability but it seems misleading, if not incorrect, to put them on the same scale. Although the probability system has its place in the strictly technical estimation of reserves, it tends to confuse rather than clarify in the murky business of reserve reporting.

So far, we have considered the reporting practices of the industry, being subject to stock exchange rules, but it is necessary to take into account those of governments and stateowned enterprises, which are not subject to these controls. Today, the bulk of the world's oil comes from such entities, so their practices have a significant influence on the world total. Here, we have to consider particularly the reporting practices of the Soviet Union and the main OPEC countries, both of which have been subject to distortion.

\section{Soviet Reserves Reporting}

The Soviet oil industry was divided into Exploration and Production arms that worked in substantial isolation, neither being subject to normal commercial criteria. The reported reserves were abstract geological volumes free of technological or economic constraints. Analysis of individual field declines shows that the official reserves have to be reduced on average by about $30 \%$ to reflect what is actually producible in the real world, as was subsequently confirmed by Khalimov (1993), the Russian expert.

\section{Opec Reserve Reporting}


The main OPEC countries expropriated the holdings of the foreign companies during the 1970s, following the precedent of Iran's action against BP in 1951. State enterprises were formed to produce the oil, inheriting the technical data and reserve estimates from the private companies. In 1985, Kuwait reported a 50\% increase to its reserves overnight although nothing particular changed in the reservoir. It did so to increase its OPEC production quota, which was based on reserves. Then three years later, Venezuela doubled its reported reserves by the inclusion of large amounts of long-known heavy oil

\begin{tabular}{|c|c|c|c|c|c|c|c|c|}
\hline & $\begin{array}{c}\text { Abu } \\
\text { Dhabi }\end{array}$ & Dubai & Iran & Iraq & Kuwait & $\begin{array}{l}\text { Veutral } \\
\text { Zone }\end{array}$ & $\begin{array}{l}\text { Saudi } \\
\text { Arabia }\end{array}$ & Venezuela \\
\hline 1980 & 28.0 & 1.4 & 58.0 & 31.0 & 65.4 & 6.1 & 163.4 & 17.9 \\
\hline 1981 & 29.0 & 1.4 & 57.5 & 30.0 & 65.9 & 6.0 & 165.0 & 18.0 \\
\hline 1982 & 30.6 & 1.3 & 57.0 & 29.7 & 64.5 & 5.9 & 164.6 & 20.3 \\
\hline 1983 & 30.5 & 1.4 & 55.3 & 41.0 & 64.2 & 5.7 & 162.4 & 21.5 \\
\hline 1984 & 30.4 & 1.4 & 51.0 & 43.0 & 63.9 & 5.6 & 166.0 & 24.9 \\
\hline 1985 & 30.5 & 1.4 & 48.5 & 44.5 & 90.0 & 5.4 & 169.0 & 25.9 \\
\hline 1986 & 30.0 & 1.4 & 47.9 & 44.1 & 89.8 & 5.4 & 168.8 & 25.6 \\
\hline 1987 & 31.0 & 1.4 & 48.8 & 47.1 & 91.9 & 5.3 & 166.6 & 25.0 \\
\hline 1988 & 92.2 & 4.0 & 92.9 & 100.0 & 91.9 & 5.2 & 167.0 & 56.3 \\
\hline 1989 & 92.2 & 4.0 & 92.9 & 100.0 & 91.9 & 5.2 & 170.0 & 58.1 \\
\hline 1990 & 92.2 & 4.0 & 92.9 & 100.0 & 91.9 & 5.0 & 257.5 & 59.1 \\
\hline 1991 & 92.2 & 4.0 & 92.9 & 100.0 & 94.5 & 5.0 & 257.5 & 59.1 \\
\hline 1992 & 92.2 & 4.0 & 92.9 & 100.0 & 94.0 & 5.0 & 257.9 & 62.7 \\
\hline 1993 & 92.2 & 4.0 & 92.9 & 100.0 & 94.0 & 5.0 & 258.7 & 63.3 \\
\hline 1994 & 92.2 & 4.3 & 89.3 & 100.0 & 94.0 & 5.0 & 258.7 & 64.5 \\
\hline 1995 & 92.2 & 4.3 & 88.2 & 100.0 & 94.0 & 5.0 & 258.7 & 64.9 \\
\hline 1996 & 92.2 & 4.0 & 93.0 & 112.0 & 94.0 & 5.0 & 259.0 & 64.9 \\
\hline 1997 & 92.2 & 4.0 & 93.0 & 112.5 & 94.0 & 5.0 & 259.0 & 71.7 \\
\hline 1998 & 92.2 & 4.0 & 89.7 & 112.5 & 94.0 & 5.0 & 259.0 & 72.6 \\
\hline 1999 & 92.2 & 4.0 & 89.7 & 112.5 & 94.0 & 5.0 & 261.0 & 72.6 \\
\hline 2000 & 92.2 & 4.0 & 89.7 & 112.5 & 94.0 & 5.0 & 259.2 & 76.9 \\
\hline 2001 & 92.2 & 4.0 & 89.7 & 112.5 & 94.0 & 5.0 & 259.3 & 77.7 \\
\hline 2002 & 92.2 & 4.0 & 89.7 & 112.5 & 94.0 & 5.0 & 259.3 & 77.8 \\
\hline
\end{tabular}

that had not previously been reported. This led Iraq, Iran, Dubai, Abu Dhabi and later Saudi Arabia to retaliate with huge increases to protect their quotas. Some revision was called for, as the earlier estimates were too low, having been inherited from the private companies before they were expropriated. But the revisions, whatever the right number might be, have to be backdated to the discovery of the fields concerned, which had been made up to fifty years before. In total about 300 billion barrels were added in this way during the late 1980s, greatly distorting the apparent discovery record. It is noteworthy 
too that in several cases the reported reserves remain implausibly unchanged for years on end despite production. It is staggering that such obviously flawed information is recorded in the public database, substantially without comment or qualification.

The expropriation of the foreign companies had far-reaching and unforeseen consequences. Had they retained control of the cheap and easy oil in the Middle East, they would have produced it before turning to the more difficult and costly oil offshore and in polar regions under a normal progression that would have drawn attention to gradual depletion, growing scarcity and rising cost. But when they lost control, they turned to the difficult and expensive sources, and they worked flat out, leaving control of the cheap and easy with the Middle East governments. The latter then found themselves facing the difficult task of exercising a swing role in making up the difference between world demand and what the other countries could produce within their depletion profiles. Furthermore, it means that when the cheap and easy oil in the Middle East peaks and declines, there is no cushion left of more difficult and costly oil to turn to. It follows that world production will fall more precipitately and with less warning than would have been the case had the industry evolved in a normal fashion.

\section{What to measure?}

Still another source of confusion is the fact that there are several different categories of oil, there being clearly a huge difference between a free flowing Middle East well and digging up a tar sand in Canada with a shovel. Each category has its own endowment in nature, its own costs and characteristics, and above all its own depletion profile. The easy and cheap categories, commonly termed Conventional, have supplied most oil to-date and will dominate all supply far into the future, but there is no standard agreement on where to draw the boundary with the Non-conventional categories.

\section{The Phase Problem}

Hydrocarbons occur in solid, liquid and gaseous phases, which is a cause of more confused reporting. In the same way as moisture in the atmosphere condenses as rain, or as bubbles form in a glass of champagne, hydrocarbon phases change under differing conditions of temperature and pressure. Saturated oils release gas, which forms a gas cap in the reservoir. Gas dissolved in oil in the reservoir may separate on being brought to the surface, being termed Condensate, which may or may not be metered with the oil. Additional liquids are extracted in gas plants. Ideally it would make sense to treat condensate with oil, where it is related to an oilfield, because it would deplete in relation to the oil, but to distinguish the liquids associated with a gas field, again because they would deplete in relation to gas production. But in practice the database is far from allowing accurate differentiation

\section{Still More Confusion}

The measurement of gas has its own problems, it being often uncertain if the reported volumes include the non-flammable components, which are often present. The flaring and re-injection of gas are further areas of uncertainty. 
If all of this was not enough, a single field often appears under different names where it crosses national or concessional boundaries. The largest hydrocarbon accumulation in the world is such a case being known as the North Field in Qatar and South Pars in Iran.

Some studies, notably that by the USGS in 2000, stress the so-called resource pyramid, claiming that the exploitable resources grow as the need arises. This notion is inherited from mining minerals or coal, where the concentration of the ore is critical. If prices rise or costs fall, lower concentrations become viable. But it fails to grasp the polarity of oil which is normally either there in profitable abundance or not there at all. The oil-water contact in a reservoir is abrupt giving virtually no possibility of tapping lower concentrations. The heavy oil and bitumen deposits, which could be considered as the lower part of the pyramid, are present in large quantities only in western Canada and eastern Venezuela.

The foregoing discussion suffices to explain the magnitude of the confusion resulting from the ambiguous definitions and lax reporting practices. It further explains how the proponents of doctrinaire flat-earth economic principles have been able to free themselves from the measurement constraints of actual discovery trends.

\section{Data Sources}

The most widely used public source of information comes from annual compilations made by the Oil \& Gas Journal and World Oil. Being trade journals, they are not in a position to verify the validity of the information they receive. It is noteworthy that the two data-sets differ greatly, despite being compiled in a similar fashion from government and industry sources. One obvious weakness is the fact that reserve estimates in many countries remain implausibly unchanged for years on end despite production, signifying that the country concerned has either not updated its estimate or has simply failed to respond. As many as sixty-three countries reported unchanged estimates in 2002.

Another widely used source is the BP Statistical Report of World Energy. Many analysts mistakenly believe that the data have at least the tacit blessing of a knowledgeable and experienced oil company that is capable of assessing their validity. But BP simply reproduces the Oil \& Gas Journal material, understandably not wishing to expose itself in this sensitive area.

There is an industry database, which has been compiled over many years in close cooperation with the oil companies, that does report full field reserves properly backdated to discovery, but its cost puts it out of range for most analysts. In earlier years when the industry was dominated by a few major companies, it was a comparatively easy task to keep track, especially as the companies themselves supported the work. But it has become increasingly difficult because the industry is more fragmented with many speculative small companies at work and because of the growing control by state companies. Furthermore, the United States and Canada operate in such a very different environment from the rest of the world that it is difficult to integrate information from those counties into the world picture. 


\section{A Flawed Study by the US Geological Survey}

The US Geological Survey has investigated the world's oil potential since the oil shocks of the 1970s. It put out sound assessments, which were published at three-year intervals until a new team issued a thoroughly flawed study in 2000. It considered its remit was to look only at abstract geological factors to indicate the amounts to be found in a 30-year study period from 1995, couching the results in terms of subjective probability, quoted to three decimal places. It singularly failed to relate its findings with past discovery and production trends, or estimate the scale of exploration required to deliver the indicated amounts. The forecast is already discredited by the actual discovery results of the first six years of the study period. Its Mean estimate of discovery over the 30-year period is 732 $\mathrm{Gb}$, giving an average of $24 \mathrm{~Gb}$ a year, when the actual results to date have been less than half that amount. This is doubly damning because the larger fields are found first. In addition, it introduced the notion of Reserve Growth, proposing that present reserves will grow by between 46 and 130 percent, with $76 \%$ being the Mean value. Failing to grasp the nature of the reporting practices as discussed above, it applied the experience of the old onshore fields of the United States to the world as a whole, despite the very different environment. It also failed to understand that reserve growth is mainly confined to large fields with several phases of development, and will not be matched in the smaller fields of the future.

Estimates of the total endowment have been published over the years by major oil companies, consultants, and other authorities. The average of some sixty-five estimates is just under two trillion barrels, although the definitions of what was being measured may have varied somewhat from author to author. At all events the ASPO estimate of 1900 $\mathrm{Gb}$ for the total amount to be produced to the year 2075 is close to the consensus.

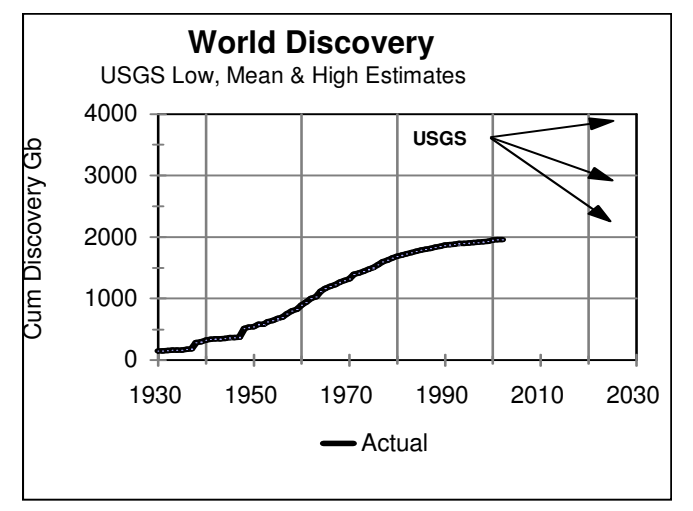

\section{The Inescapable Nature of Depletion}

The foregoing discussion has explained the extreme weakness of public data on oil discovery and production. Many analysts, lacking direct experience of the oil business, can be forgiven for taking apparently authoritative data at face value. They cannot be expected to understand the subtleties of definition and reporting practice. That said, the fact remains that oil and gas are finite resources, formed on rare occasions in the geological past. It follows that they are undeniably subject to depletion. An essential feature of depletion is that the higher the production, the shorter the life-span. The world started running out when it produced the first barrel, but "running out" is not really the key issue as the tail end of production can drag on for a long time. A museum in Pennsylvania exhibits a well, drilled over 100 years ago, yet still produces a few pints a 
day. Production in a country starts and ends at zero, reaching a peak in between when approximately half the total has been produced, as eloquently explained by M. King Hubbert, who correctly predicted when the United States would peak fifteen years before it did so (Hubbert 1956, 1962). Much more important than final exhaustion, which will not happen for many decades, is the issue of peak, when the growth of the past gives way to the decline of the future. With oil providing $40 \%$ of traded energy and $90 \%$ of transport fuel, peak is set to represent an historic discontinuity, affecting virtually all aspects of life on Earth including agriculture, which means food.

Mankind accordingly faces a huge challenge in adapting his way of life to use less oil and gas both by being less wasteful and by tapping other substitute sources of energy, none of which is likely to come close to oil in terms of cost and convenience. Whether we like it or not, logic proclaims that we desperately need to know the time available to prepare for this change, which means that we have to determine the date of peak production as well as we can. Two obstacles stand in the way. The first is the malign influence of doctrinaire economics, with its $19^{\text {th }}$ Century belief in Man as Master of his Environment on a Planet of Infinite Resources to be bent to his Will; and the second is the unreliable nature of the data in the public domain, as discussed above.

\section{Modelling Depletion}

One of the most misleading but widely used measures of depletion is the so-called Reserves to Production Ratio ( $R / P$ ratio), quoted in years, which simply divides the reserves by the current annual production. A moment's reflection shows the absurdity of the notion that current production could be held for a given number of years and then stop overnight, when all oilfields are observed to decline towards exhaustion. It is amazing that BP should publish such a misleading plot in its Statistical Review of World Energy.

Oil has to be found before it can be produced, which means that production has to mirror earlier discovery after a time-lag. Past discovery, which is fact not speculation, is accordingly the key to the future. Experience in mature areas shows that the larger fields tend to be found first, simply because they are too large to miss.

If we had access to the full industry database it would be a relatively straightforward task to analyse each geological province using three techniques

\section{Creaming Curve}

The simple creaming curve plots cumulative discovery over time but the results are subject to distortion due to external events such as wars or government exploration policies. A better method is to plot cumulative discovery against cumulative wildcats. It will be noted that the discovery normally follows one or more hyperbolic trends. Extrapolation of the hyperbola to asymptote allows calculation of what is left to find, subject to an economic cut off for fields too small to be economic. A convenient method is to build the hyperbola on three input parameters: a) first discovery; b) discovery at half the current number of wildcats; and c) discovery to-date. 


\section{Parabolic Fractal}

Jean Laherrère (1996) has described a fractal law whereby the size distribution of objects in a natural domain plot as a parabola when size is set against rank on log-log scales. When all the larger fields have been found, they provide a

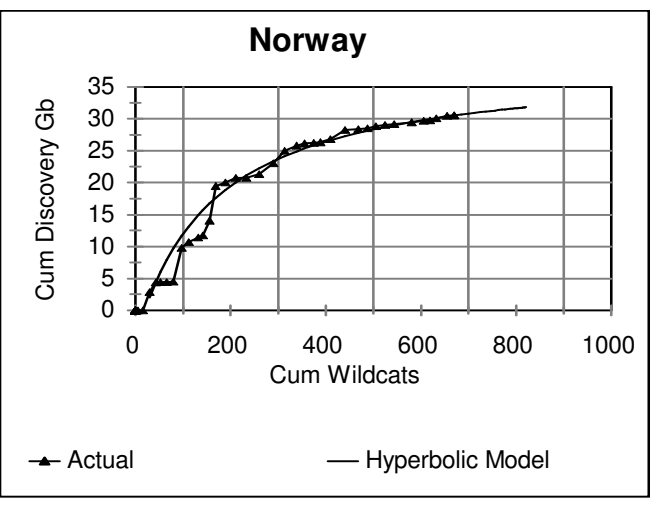
complete segment of the distribution, which by a fractal law of self-similarity describes the whole, thereby setting the parameters by which to construct a parabola to the smallest field. The difference between the discovery to-date and the total defined by the parabola gives what is left to find.

\section{Discovery-Production}

A third method is to smooth discovery and then correlate it with corresponding production after a time-lag. It is commonly easy to spot the peak of discovery and use the subsequent decline to show the corresponding decline of future production. It may be helpful to smooth the cycle with a classic bell-curve. Some countries have had more than one cycle of discovery and production.

\section{A pragmatic model}

The ASPO network (see endnote) has published production, reserve and discovery data by country based on public and industry information, doing its best to remove the anomalies discussed above. Given the less than reliable input, it does not claim to be more than a fair approximation, sufficient to determine the peak of production within a tolerable range of uncertainty (see Tables 1 and 2.)

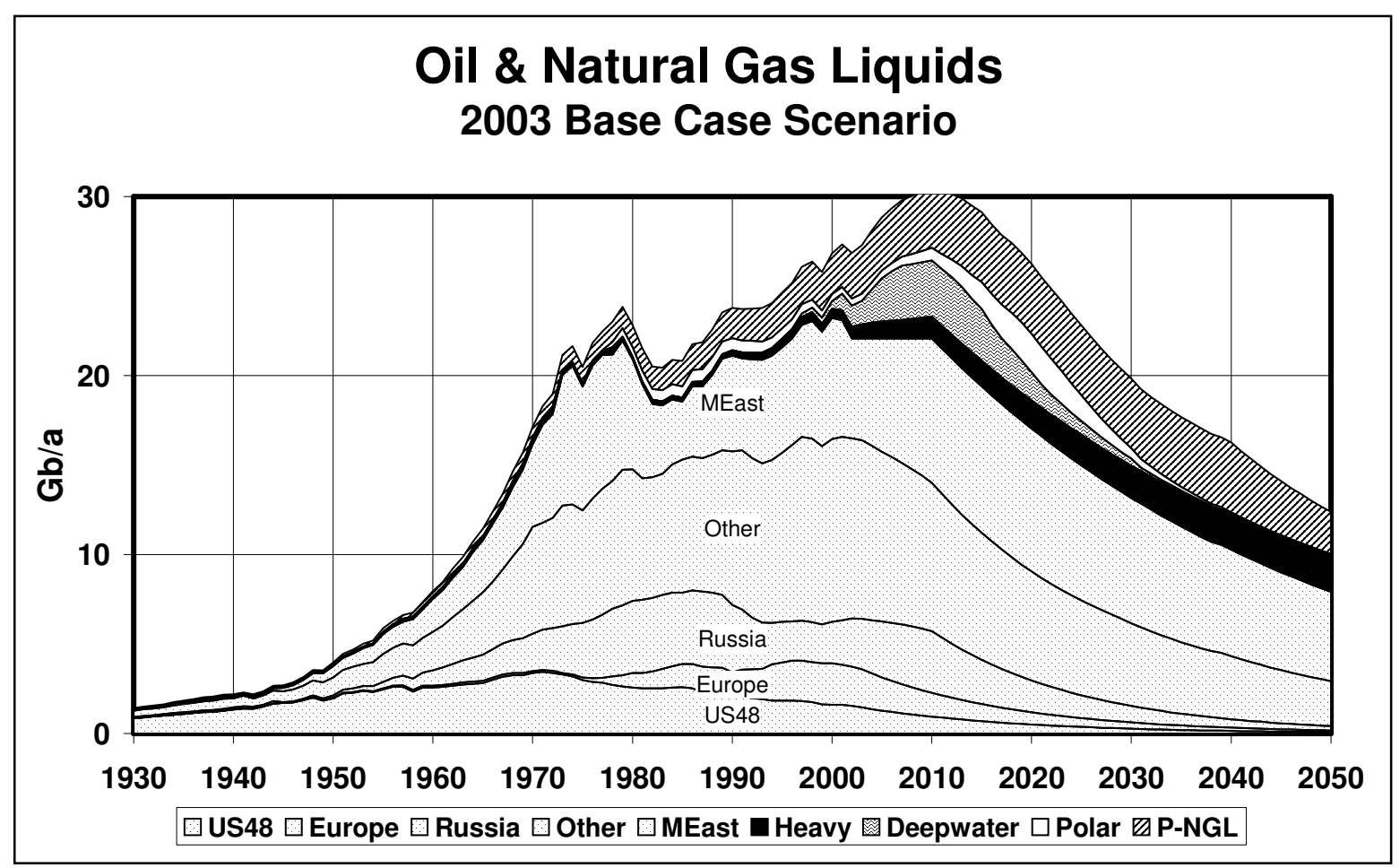


In the absence of comprehensive detailed data, it has adopted a simple depletion model based on the following assumptions:

\section{Post-Midpoint countries}

It is assumed that production in countries that have produced more than remains will continue to decline at the current Depletion Rate, namely annual production as a percentage of the amount left to produce.

2. Pre-Midpoint countries

Production is assumed to be flat to midpoint in countries that have not yet reached it, save where local circumstances suggest otherwise. The assumptions are not very critical to the long term forecast because most such countries are now within only a few years of midpoint. Production is assumed to decline from midpoint at the then Depletion Rate

3. Swing countries

The five major producers of the Middle East, namely Abu Dhabi, Iraq, Iran, Kuwait and Saudi Arabia (including the Neutral Zone), with about half the world's remaining oil are treated as swing producers making up the difference between world demand and what the other countries can produce under the model. The Base Case Scenario assumes that world demand will be on average flat to 2010 due to recurring recessions and price spikes as the oil production capacity limits are breached.

It is to be expected that actual production will depart from the forecast for all sorts of extraneous short-term reasons, but the model self-adjusts to a degree. If production temporarily rises above forecast that would increase the depletion rate, meaning that the forecast subsequent decline would be steeper to respect the total endowment of the country.

Provision in the model is made for the entry of Non-conventional oil and liquids produced from gas plants as follows:

\section{Heavy Oils}

The production of Extra-Heavy Oil and Bitumen, principally in Canada and Venezuela, together with synthetic oils made therefrom, is expected to grow slowly. The Canadian operations are constrained by the mammoth scale of the task, the shrinking supplies of cheap gas to fuel the plants, water supply limits and the need to excavate ever-greater thicknesses of overburden to reach the deposit, in what is effectively a mining operation. It may even be necessary to build nuclear plants to produce the steam used in the extraction process. It is important to remember that so far only the more favourable locations have been exploited.

An arbitrary cut-off for Heavy Oil is set at a density of $17.5^{\circ}$ API. Some of it may be produced in normal wells, but it is characterised by low production rates and a low recovery factor, which in turn makes it susceptible to enhanced recovery by steam injection and other methods. Many claims are made that technology will increase the percentage of the oil recovered from a reservoir, failing to grasp that it is the physical properties of the oil and the reservoir that mainly control the immovable portion held in the rock. 


\section{Deepwater Oil (>500m)}

It seems clear that the prime areas for deepwater discovery are the Gulf of Mexico and the margins of the South Atlantic, especially off Angola and Brasil, where the appropriate geological conditions are met. Deepwater prospects elsewhere are largely confined to the delta fronts themselves, which are likely to be gas prone with only limited oil potential. Production in deep water tests management and technological skills to the limit and is also somewhat constrained by the availability of floating production equipment. Approximately $35 \mathrm{~Gb}$ have been discovered so far, out of a total estimated endowment of about $65 \mathrm{~Gb}$.

\section{Polar Oil}

Antarctica has limited prospects, being in any case closed to exploration by agreement. The Arctic regions are more promising with some huge sedimentary basins. But the evidence to date suggests that they are mainly gas-prone due to vertical movements of the crust under the weight of fluctuating ice caps in the geological past which have depressed such source rocks as are present into the gas window and have also tended to destroy seal integrity. Alaska is something of an anomaly, having been buttressed by the Rocky Mountains. It is a concentrated geological habitat, having most of its oil in the Prudhoe Bay field. Even so, some provision is made for new polar oil discoveries, mainly in the Siberian Arctic.

\section{Natural Gas Liquids}

The production of gas plant liquids is expected to grow in parallel with gas, with some anticipated increase in yield.

\section{Oil Price}

Non-Swing conventional oil production has been almost flat since 1997. It would have been natural to expect oil prices to have risen, reflecting the growing control of the market by the Middle East, but in fact prices collapsed in the following year due to an Asian recession and other anomalous factors. They then rebounded with a staggering 300\% increase during 1999 and 2000, and could have gone much higher, as the world had about run out of spare capacity, but recession intervened,

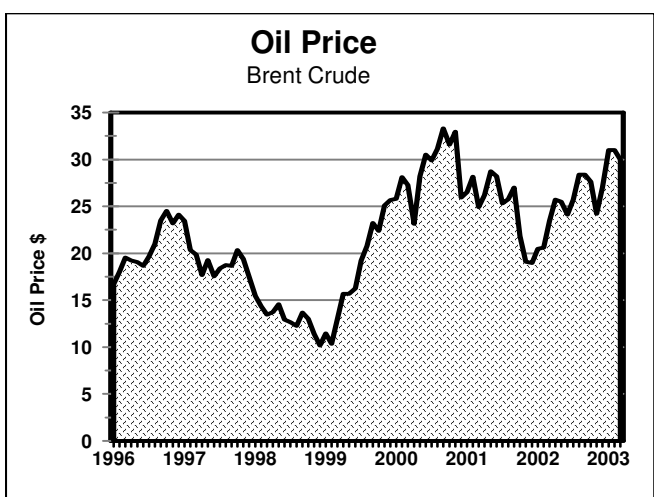
partly reflecting the increase in price itself, dampening demand and reducing pressure on price. It appears therefore that the world has entered a vicious circle whereby any improvement in the economy would lead to increased oil demand that would again soon hit the falling capacity limit causing higher prices that would in turn re-impose recession. Oil is priced on the availability of the marginal barrel: a better system would be to price it on the cost of a substitute fuel. 
The issue of spare capacity is yet another confusing matter. It is evident that the oil companies are now producing flat out everywhere, having virtually no spare capacity. It seems most unlikely that the Middle East countries, not having the tax subsidies enjoyed by private companies, would dig into their already stretched national budgets to drill wells and then shut them in simply to provide a comforting cushion for the consumers. It is only a shut-in well that can be opened at will. Production can be stepped up briefly in any field, but overproduction for any length of time can do irreparable damage to the reservoir.

With the world now finding less than one barrel for every four it consumes, the pressure on capacity can only increase in the future. The gap is growing wider.

It should be noted that the model makes no provision for the impact of the threatened invasion of Iraq, which may well lead to years of terrorism and sabotage throughout the Middle East and

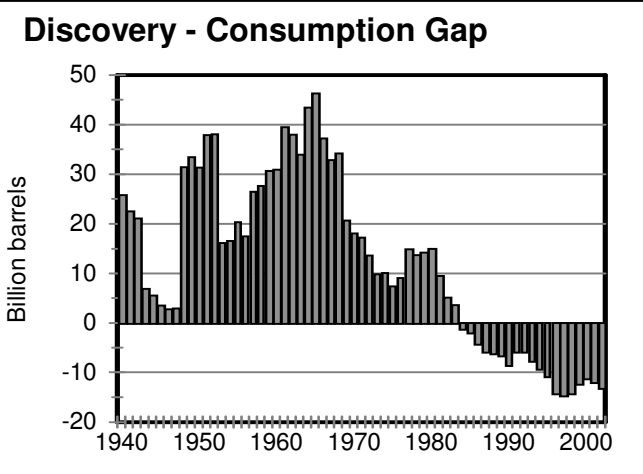
elsewhere. If so, history may yet show that conventional oil production in fact already peaked in 2000, with the Middle East being no longer able to offset the natural decline elsewhere as is assumed in the Base Case Scenario. Some analysts already see this possibility (Groppe, 2002).

\section{Gas Depletion}

Gas was more widely generated in Nature than was oil, but that advantage is offset by the fact that it needs a better seal to hold it in the reservoir, much having escaped over geological time. The higher molecular mobility of gas means that a greater percentage is recoverable - about $80 \%$ compared with around $40 \%$ for oil - and it is subject to a very different depletion profile. An uncontrolled well would deplete a gas accumulation very quickly, so in practice production is capped to provide a long plateau, with most fluctuation being seasonal. In an environment such as the United States, gas from a large number of suppliers is fed into a pipeline network. They vie with each other in drawing down their inbuilt spare capacity. Costs fall as the original investments are written off, and prices move downward in a competitive market, attracting new customers, especially in the form of electricity generators, attracted also by the environmental benefits of gas. But eventually the inbuilt capacity is exhausted without market signals, causing production to collapse, as is occurring in the United States. Gas drilling has surged there as a consequence, but this time the wells are produced at maximum rate being depleted in a matter of months. The failure of the United States government to recognise the easily predictable consequences of depletion may go down in history as one of its worst failures. Other countries are no better: the United Kingdom now also faces a rapid decline in indigenous gas supply, with imports set to pass $50 \%$ by 2010 .

Whereas oil is a flexible global market, gas is more regional in nature reflecting the higher cost and constraints of pipeline transport. Much gas is stranded in remote areas far from market. Gas may be liquefied at low temperature and transported in costly special 
tankers. It may also be converted into liquids directly under a variant of the Fischer Tropff process that produces liquid hydrocarbons from coal.

Current estimates suggest that the total endowment of gas is about $10000 \mathrm{Tcf}$ (trillion cubic feet), of which about 2700 Tcf have been produced to-date. North American production already peaked in 1973 and now faces a precipitate fall. Europe can continue to rely for a few years on Norwegian gas supplemented by increasing imports from North Africa, Siberia and eventually the Middle East and Central Asia, partly competing with South East Asia for such supplies. Other regions rely on local sources. It is difficult to model overall depletion, but it is reasonable to contemplate a plateau of about $130 \mathrm{Tcf}$ a year from 2015 to 2040 followed by a steep decline. Non-conventional gas, principally from coalbed methane, will no doubt supplement conventional supplies, already contributing about $10 \%$ of US needs. Gas hydrates, which attract a great deal of misplaced research funding, can be confidently dismissed as a realistic source of commercial gas.

\section{Conclusions}

This short paper has endeavoured to outline the scientific evidence for expecting oil production to peak in the near future. Few can doubt the importance of the subject, given that oil and gas fuel the modern economy. There are no particular difficulties in making valid estimates of the size of an oilfield nor in extrapolating the discovery trends of the past to indicate what is left to find and produce. It will be also noted in this connection that the world has been very thoroughly explored by an industry using advanced technology and well established scientific knowledge. Furthermore the industry has deliberately aimed at the biggest and best prospects, and it has worked under a favourable economic environment whereby the cost of exploration is substantially subsidized under the tax regime. If more could have been found, it would have been, implying that the long decline in discovery since the 1960s, as now confirmed by the oil industry itself (Longwell 2002), reflects the limits imposed by Nature.

These fairly obvious and unassailable conclusions have been obscured by the extremely unreliable nature of public data due to ambiguous definitions and lax reporting practices. Furthermore they reveal an unpalatable truth that runs in the face of established mind-sets and the pervasive precepts of classical economics, that were built on $19^{\text {th }}$ Century experience.

Yet, however uncomfortable the message, the fact remains that the world is depleting its resources of oil and gas, such that production is set to peak and begin to decline by around 2010. World population has risen six-fold almost exactly in parallel with soaring oil production, which provided a critical energy source to drive the world's economy, including its agriculture by which to feed the people.

While the precise date of peak can not be established with absolute accuracy, being influenced by changes in demand due to recession, war and other factors, it comes soon enough to be of very serious concern to Mankind. It is evident that ways will have to be found within this generation to curb the present waste of energy and find substitutes for 
essential needs. The transition and adjustment to the changed circumstances will not be easy, so the sooner the plans are made the better. They will likely include moves to a more central style of government as the famous open market is not designed to manage depletion of a critical resource. The concentration of what is left to produce in a few Middle East countries is a source of geopolitical conflict that may erupt into war as countries vie with each other for access (Klare, 2002). There is a great deal at stake.

\section{References}

Adelman M.A., 1995, The genie is out of the bottle: world oil since 1970; MIT ISBN 0262-01151-4

ASPO Newletters (see www.asponews.org)

Bentley, R W., 2002, Global oil \& gas depletion: an overview; Energy Policy 30, p 189205, 2002

Campbell C.J., 1997, The Coming Oil Crisis; Multi-Science Publishing Co. \& Petroconsultants $210 \mathrm{p}$

Campbell C.J., and J.H. Laherrère, 1998, The end of cheap oil; Scientific American March 80-86

Deffeyes K.S.,2001, Hubbert's peak - the impending world oil shortage; Princeton University Press 208pp

Gold T., 1988, Origin of petroleum; two opposing theories and a test in Sweden; Geojournal Library 9 85-92.

Groppe H, 2002, The world oil and US natural gas outlook; Executive Oil Conference, Midland Texas 17 April 2002

http://www.petroleumstrategies.com/eocpresentations/2002/Groppe.ppt

Hubbert M.K., 1956, Nuclear energy and the fossil fuels; Amer. Petrol. Inst. Drilling \& Production Practice. Proc. Spring Meeting, San Antonio, Texas. 7-25.[\#187]

Hubbert M.K., 1962, Energy resources, a report to the Committee on Natural Resources; Nat. Acad. Sci. Publ. 1000D

Ivanhoe, L F., 2000, World Oil Supply-Production, Reserves, and EOR; Hubbert Center Newsletter \# 2000 / 1-1, January 2000

Khalimov E.M.,1993, Classification of oil reserves and resources in the former Soviet Union; Amer. Assoc. Petrol. Geol. 77/9 1636 (abstrct)

Klare M.T., 2002, Resource Wars; Owl Books 289p.

Laherrère J.H., 1996, Distributions de type "fractal parabolique" dans la Nature: C.R.Acad. Sci. Paris 322 II

Laherrère J.H., 1999, Reserve growth: technological progress, or bad reporting and bad arithmetic Geopolitics of Energy

Longwell H.,2002, The future of the oil and gas industry: past approaches ,new challenges; World Energy 5/3 2002

Odell P, R., 1999, Fossil fuel resources in the 21 st Century; Financial Times Energy

Perrodon A., 1999, Quel pétrole demain, Technip, Paris 94p

Simmons, M R., 2000, Energy in the New Economy: The Limits to Growth; Energy Institute of the Americas, October 2, 2000

United States Geological Survey (2000) World Petroleum Assessment; DDS-60.

Youngquist W., 1997, Geodestinies: the inevitable control of earth resources over nations and individuals; Nat. Book Co., Portland 500p. 
ASPO is a network of scientists, affiliated with European institutions and universities, having an interest in determining the date and impact of the peak and decline of the world's production of oil and gas, due to resource constraints.

It presently has members in: Austria, Denmark, Finland, France, Germany, Ireland, Italy, Netherlands, Norway, Portugal, Sweden, Switzerland and the United Kingdom.

Mission:

1. To evaluate the world's endowment of oil and gas;

2. To model depletion, taking due account of economics, technology and politics;

3. To raise awareness of the serious consequences for Mankind. 